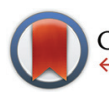

CrossMark \& click for updates

Cite this: Dalton Trans., 2015, 44 2819

Received 24th October 2014, Accepted 5th December 2014

DOI: 10.1039/c4dt03283g

www.rsc.org/dalton

\title{
Structural and luminescence studies of the new nitridomagnesoaluminate $\mathrm{CaMg}_{2} \mathrm{AlN}_{3}$
}

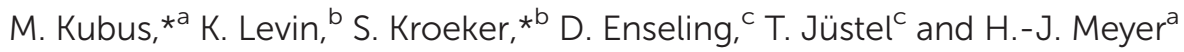

$\mathrm{CaMg}_{2} \mathrm{AlN}_{3}$ was synthesized in a closed system by solid state reaction from binary nitrides. Structure refinements based on powder $\mathrm{X}$-ray diffraction data suggested ambiguity about the occupancy of magnesium and aluminum tetrahedral sites. Solid-state ${ }^{27} \mathrm{Al}$ and ${ }^{25} \mathrm{Mg}$ NMR studies were used to adjudicate amongst possible space groups. With reference to projector augmented wave calculations of the quadrupolar coupling constants, the measured values of $C_{Q}$ and the numbers of crystallographically inequivalent $\mathrm{Al}$ and $\mathrm{Mg}$ sites indicate that $\mathrm{CaMg}_{2} \mathrm{AlN}_{3}$ crystallizes in the space group $P 6_{3} / m m c$ with partial occupancy of the distorted tetrahedral $\mathrm{Al}$ site and possibly also mixing of $\mathrm{Mg}^{2+}$ and $\mathrm{Al}^{3+}$ ions on opposite sites. The compound obtained by synthesis with a flux shows orange defect-related luminescence at room temperature.
\end{abstract}

\section{Introduction}

Many new ternary and quaternary nitrides have been obtained in recent years, however their synthesis is very challenging because of required synthesis conditions and reaction partners. The reactants and products are often easily hydrolyzed or oxidized in air. ${ }^{1}$ Preparations of nitrides with a highly condensed network structure are mainly performed by high-temperature solid state syntheses. ${ }^{2}$ However, it is also possible to synthesize such nitrides at low temperature via solid state metathesis reactions. ${ }^{3}$ A steady increase in the importance of nitride-based materials is devoted to the employment of these materials as host structures of phosphors. The temperature and pressure conditions for the production of the nitridebased phosphors are crucial because the starting materials behave chemically inert in reactions. ${ }^{4}$ A flux agent can be used to enhance the yield of nitrides synthesis, e.g. molten sodium,${ }^{5}$ or liquid lithium. ${ }^{6}$ In many cases pure nitrides without oxygen impurities are difficult to make and special attention should be paid to the choice of substrates. ${ }^{7}$

Ternary nitrides can be divided into two groups, intermetallic with dominant metal-metal interactions and ionic/covalent where metal-nitrogen bonding is dominant. Intermetallic

\footnotetext{
${ }^{a}$ Section for Solid State and Theoretical Inorganic Chemistry, Institute of Inorganic Chemistry, Eberhard-Karls-Universität Tübingen, Auf der Morgenstelle 18, 72076 Tübingen, Germany.E-mail: mariusz.kubus@anorg.uni-tuebingen.de; Fax: +49-(0)7071-29-5702

${ }^{b}$ Department of Chemistry, University of Manitoba, Winnipeg, Manitoba, R3T 2N2, Canada.E-mail: scott.kroeker@umanitoba.ca

${ }^{c}$ Labor für Angewandte Materialwissenschaften, Fachhochschule Münster,

Stegerwaldstrasse 39, 48565 Steinfurt, Germany
}

nitrides with ionic or covalent bonds may have many different metal-anion coordination environments with structures related to oxides or sulfides. ${ }^{8}$

Nitridosilicates, nitridoaluminosilicates, oxonitridosilicates, and oxonitridoaluminosilicates are usually constructed of $\left[\mathrm{M}(\mathrm{N}, \mathrm{O})_{4}\right]$ tetrahedra $(\mathrm{M}=\mathrm{Al}, \mathrm{Si})$ which are connected with each other to form isolated polyhedra, or one-, two- and threedimensional structures. ${ }^{2,9}$ For example edge-bridged dimers of tetrahedra were reported as $\left[\mathrm{Al}_{2} \mathrm{~N}_{6}\right]^{12-}$ in the structure of $\mathrm{Ca}_{6} \mathrm{Al}_{2} \mathrm{~N}_{6} \cdot{ }^{10}$ One-dimensional chains of edge sharing $\left[\mathrm{AlN}_{4}\right.$ ] units contain $\mathrm{M}_{3} \mathrm{Al}_{2} \mathrm{~N}_{4}$ structures with $\mathrm{M}=\mathrm{Sr}$ and $\mathrm{Ba} .{ }^{10}$ Twodimensional sheets built from corner- and edge-sharing tetrahedra are found in $\mathrm{MMg}_{2} \mathrm{~N}_{2}$ with $\mathrm{Ca}$ and $\mathrm{Sr}^{11}$ Layered structures also appear for $\beta-\mathrm{Ca}_{3} \mathrm{Al}_{2} \mathrm{~N}_{4}$ and $\mathrm{LiCaAlN}_{2}$ containing edge- and vertex-sharing $\left[\mathrm{AlN}_{4}\right]$-tetrahedra. ${ }^{11 b, 12} \mathrm{An}$ important nitride is $\mathrm{CaAlSiN}_{3}$ with a three-dimensional network structure built from vertex-sharing $\left[(\mathrm{Si}, \mathrm{Al}) \mathrm{N}_{4}\right]$-tetrahedra forming $\left[(\mathrm{Si}, \mathrm{Al})_{6} \mathrm{~N}_{6}\right]$ rings. $^{2} \mathrm{CaAlSiN}_{3}$ doped with $\mathrm{Eu}^{2+}$ ions is one of the most successfully commercialized nitride which can be used in LEDs. ${ }^{13}$ In view of the technological significance of this material, we have targeted the closely related compound, $\mathrm{CaMg}_{2} \mathrm{AlN}_{3}$, by complete substitution of silicon by magnesium, resulting in a unique luminescent nitride which does not require doping by activator elements.

Solid-state NMR is becoming increasingly common as a complementary tool in the determination of crystal structures, particularly for materials possessing some degree of disorder or lacking sufficiently large crystals for single-crystal X-ray crystallography. ${ }^{14}$ Along with high-level computations of magnetic shielding and electric field gradients, precisely measured NMR parameters can provide key constraints on atomic positions, local symmetry elements and the number of crystallo- 
graphically inequivalent sites. Improvements in hardware and methodology continue to expand the range of nuclei for which structurally informative NMR spectra may be obtained.

\section{Experimental section}

\section{Synthesis}

Preparation of the reaction mixture for the synthesis of $\mathrm{CaMg}_{2} \mathrm{AlN}_{3}$ was performed under argon atmosphere inside a glove box. The reaction carried out in a fused niobium reaction container, sealed into a silica ampoule. $128 \mathrm{mg} \mathrm{Mg}_{3} \mathrm{~N}_{2}$ (Alfa Aesar, 99.6\%) with $94 \mathrm{mg} \mathrm{Ca}_{3} \mathrm{~N}_{2}$ (Aldrich, 99\%), and $78 \mathrm{mg}$ AlN (ABCR, grade C) were mixed in an agate mortar. For luminescent applications the material was synthesized additionally with $10 \mathrm{wt} \%$ of a flux. The flux was a mixture of LiCl (Sigma, 99.0\%) with KCN (Merck, 96\%) in molar ratio one to one.

The mixtures were heated in a furnace to $1100{ }^{\circ} \mathrm{C}$ with a heating rate of $2{ }^{\circ} \mathrm{C} \mathrm{min}^{-1}$, held at this temperature for $48 \mathrm{~h}$, and cooled to room temperature with rate $2{ }^{\circ} \mathrm{C} \mathrm{min}^{-1}$. The containers were opened under argon atmosphere, and the products were quickly flushed with dry ethanol in order to remove any possible impurities. The reaction product was analyzed by powder X-ray diffraction measurements.

\section{X-Ray diffraction}

Powder X-ray diffraction measurements were carried out with a powder diffractometer (Stoe, STADI-P, Ge-monochromator) using $\mathrm{CuK}_{\alpha 1}(\lambda=154.06 \mathrm{pm})$ radiation.

\section{N/O analysis}

All nitrogen and oxygen contents were determined using a TC-400C from Leco Corporation, equipped with TCWin Analysis software, version 4.03, and Helium 4.6 (Westfalen) as purge gas. For every analysis between $10-20 \mathrm{mg}$ of the material were weighed, transferred into tin capsules and sealed. For a more homogeneous combustion three scraps of highly pure nickel wire were added. The subsequent analysis was conducted at $1000 \mathrm{~A}$ in high purity carbon crucibles and repeated three times.

\section{Nuclear magnetic resonance spectroscopy}

${ }^{27} \mathrm{Al}$ MAS NMR was performed on a Varian Inova $600\left(B_{0}=\right.$ $14.1 \mathrm{~T})$ spectrometer $\left(\nu_{0}=156.3 \mathrm{MHz}\right)$ with a $1.6 \mathrm{~mm}$ TR Varian-Chemagnetics MAS probe at a $30 \mathrm{kHz}$ rotational frequency. 200k transients were co-added using the Bloch-decay sequence with an optimized recycle delay of $1 \mathrm{~s}$ and excitation pulse of $0.5 \mu \mathrm{s}$ ( $c a .40^{\circ}$ tip angle). The frequency axis is referenced to $1 \mathrm{M} \mathrm{Al}\left(\mathrm{NO}_{3}\right)_{3}$ (aq.) at $0 \mathrm{ppm}$.

${ }^{25} \mathrm{Mg}$ NMR was done on a Bruker Avance II $900 \mathrm{MHz}\left(B_{0}=\right.$ $21.1 \mathrm{~T})$ spectrometer. The rotor-synchronized spin-echo MAS NMR spectrum was collected with a $4 \mathrm{~mm}$ low- $\gamma$ probe at a rotor spinning frequency of $18 \mathrm{kHz}$, a recycle delay of 1 second and $60 \mathrm{k}$ scans. ${ }^{25} \mathrm{Mg}$ quadrupole-echo NMR spectra of a nonspinning sample were collected with a $5 \mathrm{~mm}$ low- $\gamma$ probe using an optimized recycle delay of 1 second and 54k scans. Chemical shifts are referenced to $1 \mathrm{M} \mathrm{MgCl}_{2}$ (aq.) at $0 \mathrm{ppm}$.

Spectral fits were achieved using WSOLIDS and dmfit. ${ }^{15}$ All samples were handled in a glove box under a dry nitrogen atmosphere.

\section{Quantum chemical calculations}

Density functional theory (DFT) calculations were performed using CASTEP, ${ }^{16}$ which incorporates GIPAW optimized for the calculation of electronic properties in periodic solids. ${ }^{17}$ Calculations implemented Perdew-Burke-Ernzerhof (PBE) functionals. Fine accuracy plane-wave basis sets with a $400 \mathrm{eV}$ cutoff were used. The CASTEP code was run in the Materials Studio 4.4 environment on an HP xw4400 workstation with a single Intel Dual-Core $2.67 \mathrm{GHz}$ processor and $8 \mathrm{~GB}$ DDR RAM.

The input data for the GIPAW calculations used the experimental lattice parameters and atomic coordinates. Geometry optimizations allowed atomic positions to change within fixed lattice parameters and space-group symmetry. The construction of supercells maintained the atomic positions found by $\mathrm{X}$-ray refinement but removed some atoms to mimic partial occupancy.

\section{Luminescence spectroscopy}

Excitation and emission spectra were recorded with an Edinburgh Instruments FSL920 spectrometer equipped with a $450 \mathrm{~W}$ Xe arc lamp, mirror optics for powder samples and a cooled $\left(-20^{\circ} \mathrm{C}\right)$ single-photon counting photomultiplier from Hamamatsu (R2658P). The correction file for the emission spectra was obtained from a tungsten incandescent lamp certified by the NPL (National Physics Laboratory, UK).

\section{Results and discussion}

In the past, relatively little attention has been paid to magnesium nitride compounds and many of them may not be structurally characterized. As expected magnesium nitrides should form a similar structural diversity as the $\mathrm{Ca}, \mathrm{Sr}$ or $\mathrm{Ba}$ compounds and only recently new materials such as $\mathrm{SrMg}_{3} \mathrm{GeN}_{4}, \mathrm{SrMg}_{2} \mathrm{Ga}_{2} \mathrm{~N}_{4}, \mathrm{MMg}_{2} \mathrm{Al}_{2} \mathrm{~N}_{4}(\mathrm{M}=\mathrm{Ca}, \mathrm{Sr}$, $\mathrm{Ba}, \quad \mathrm{Eu}), \quad \mathrm{BaMg}_{2} \mathrm{Ga}_{2} \mathrm{~N}_{4}, \quad \mathrm{Mg}_{3} \mathrm{GaN}_{3}, \quad \mathrm{Li}_{2-x} \mathrm{Ta}_{2+x} \mathrm{~N}_{4}, \quad \mathrm{Mg}_{2.6-x^{-}}$ $\mathrm{Ta}_{1.3+x} \mathrm{~N}_{4}, \mathrm{BaMg}_{3.33} \mathrm{M}_{0.67} \mathrm{~N}_{4}(\mathrm{M}=\mathrm{Nb}, \mathrm{Ta}), \mathrm{Li}_{0.51} \mathrm{Mg}_{2.49} \mathrm{~N}_{1.83}$ or $\mathrm{Li}_{1.12} \mathrm{Mg}_{0.88} \mathrm{~N}_{0.96}$ were obtained and described. ${ }^{1,9 a, 18}$

The new nitridomagnesoaluminate compound $\mathrm{CaMg}_{2} \mathrm{AlN}_{3}$ was prepared at $1100{ }^{\circ} \mathrm{C}$ in a straightforward manner from $\mathrm{Mg}_{3} \mathrm{~N}_{2}, \mathrm{Ca}_{3} \mathrm{~N}_{2}$, and AlN (1).

$$
2 \mathrm{Mg}_{3} \mathrm{~N}_{2}+\mathrm{Ca}_{3} \mathrm{~N}_{2}+3 \mathrm{AlN} \rightarrow 3 \mathrm{CaMg}_{2} \mathrm{AlN}_{3}
$$

The obtained product exhibited sensitivity to moist air and had to be kept under inert air conditions. An N/O-analysis did not indicate a significant substitution of nitride versus oxide in the structure of $\mathrm{CaMg}_{2} \mathrm{AlN}_{3}$. The overall oxygen content according to the measurement was about $0.6 \%$.

The crystal structure of $\mathrm{CaMg}_{2} \mathrm{AlN}_{3}$ is closely related to the structures of $\mathrm{ScAl}_{3} \mathrm{C}_{3}(a=3.355(1) \AA, c=16.776(3) \AA)^{19}$ and 
Table 1 Crystal parameters, atomic positions, and Rietveld quality parameters of the structure refinement of $\mathrm{CaMg}_{2} \mathrm{AlN}_{3}$

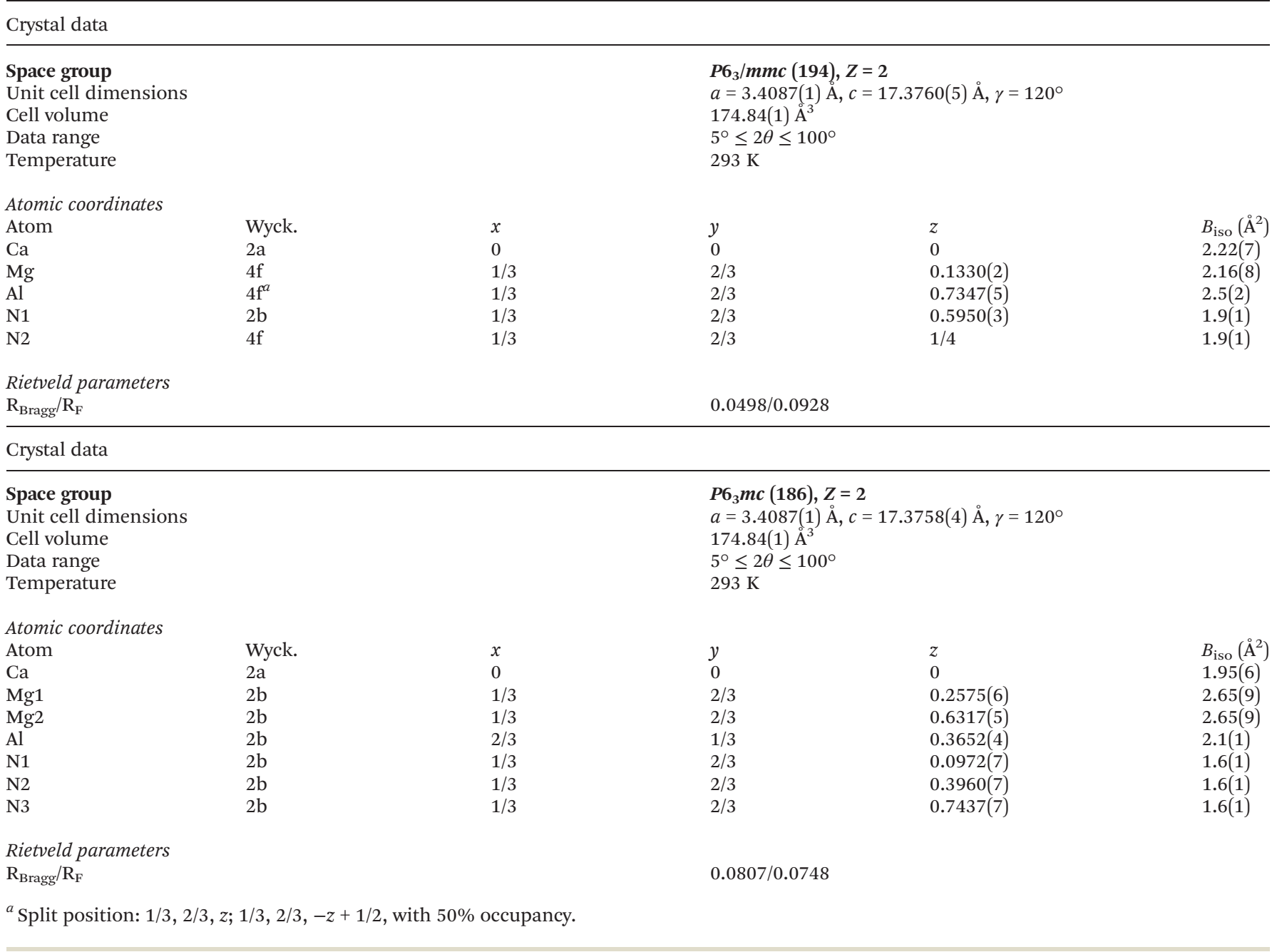

$\mathrm{UAl}_{3} \mathrm{C}_{3}(a=3.389(1) \AA, c=17.394(3) \AA) .{ }^{19}$ The crystal structure determination of these compounds was not straightforward. Reminiscent of previous work on carbides, the refinements of the $\mathrm{ScAl}_{3} \mathrm{C}_{3}$ and $\mathrm{UAl}_{3} \mathrm{C}_{3}$ were performed in the high-symmetry space group $P 6_{3} / m m c$ with a large displacement parameter for one aluminum position or, alternatively, with a split aluminum position. ${ }^{20}$ Afterwards, the crystal structures were redetermined with full occupancy of the aluminum sites in the space group $P 6_{3} m c .{ }^{19}$ The main difference between the structural results is a trigonal bipyramidal, or split tetrahedral environment of aluminum in the space group $P 6_{3} / m m c$, and a tetrahedral environment when the structures are refined in the space group $P 6_{3} \mathrm{mc}^{19}$

A similar picture is evident in the case of aluminum ions in the structure of $\mathrm{CaMg}_{2} \mathrm{AlN}_{3}$. An analysis of the extinction conditions in the X-ray diffraction data set clearly leads to the space groups $P 6_{3} / m m c$ and $P 6_{3} m c$, including related subgroups and supergroups. Structure refinements for $\mathrm{CaMg}_{2} \mathrm{AlN}_{3}$ were carried out in both space groups by the Rietveld method using the FullProf-WinPLOTR software, with the results displayed in Table 1 and Fig. $1 .^{21}$
The structure refinement in $P 6_{3} / m m c$ resulted in a $50 \%$ split position of the $\mathrm{Al}^{3+}$ ions on a $4 \mathrm{f}$ site, introducing alternating occupations of two closely adjacent $\mathrm{Al}^{3+}$ positions (0.44(2) § apart from each other) as a result of presence of a mirror plane perpendicular to the crystallographic $c$-axis at $z=1 / 4,3 / 4 . \mathrm{Mg}^{2+}$ ions occupy another $4 \mathrm{f}$ site in a regular manner (Fig. 1, at left). The coordination environment of the aluminum ion in the structure of $\mathrm{CaMg}_{2} \mathrm{AlN}_{3}$ is trigonal pyramidal with one long distance to the N1 atom parallel to the $c$-axis direction (Table 2). The combination of both closely adjacent (split) $\mathrm{Al}^{3+}$ sites into one would introduce a trigonal bipyramidal environment. A trigonal coordination environment of $\mathrm{Al}$ ions in nitrides appears unknown to us, but has been reported for $\left[\mathrm{GaN}_{3}\right]$ units in nitrides, e.g. $\mathrm{Sr}_{3} \mathrm{GaN}_{3}$ or $\mathrm{Sr}_{6} \mathrm{GaN}_{5} \cdot{ }^{22} \mathrm{~A}$ similar trigonal bipyramidal coordination was found for magnesium ions in $\mathrm{Mg}_{3} \mathrm{BN}_{3} \quad\left(\mathrm{PG}_{3} / \mathrm{mmc}\right)$ whose structure appears somehow related to that of $\mathrm{CaMg}_{2} \mathrm{AlN}_{3} \cdot{ }^{23}$

According to the structure refinement of $\mathrm{CaMg}_{2} \mathrm{AlN}_{3}$ with the non-centrosymmetric space group $\mathrm{P}_{3} \mathrm{mc}$, two $\mathrm{Mg}^{2+}$ ions occupy two $2 \mathrm{~b}$ sites, and one $\mathrm{Al}^{3+}$ ion occupies another $2 \mathrm{~b}$ site, 


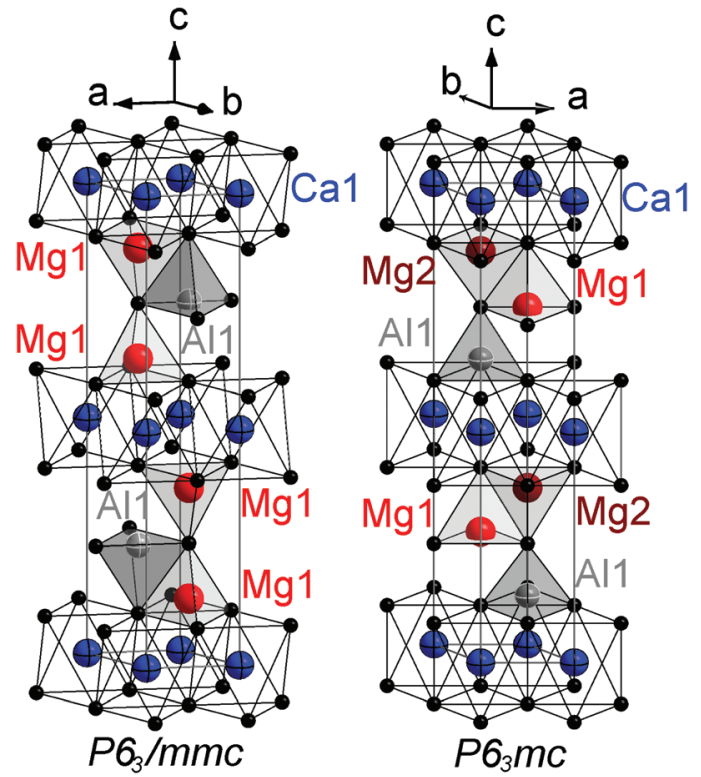

Fig. 1 Projection of the crystal structure of $\mathrm{CaMg}_{2} \mathrm{AlN}_{3}$, space group $P 6_{3} / m m c$ (left) and $P 6_{3} m c$ (right), with highlighted $\left[\mathrm{MgN}_{4}\right]$ tetrahedra (grey), $\left[\mathrm{AlN}_{4}\right]$ tetrahedra (dark grey), and $\left[\mathrm{CaN}_{6}\right]$ octahedra (transparent). Al and $\mathrm{Mg}$ occupy two crystallographic (4f) sites in $\mathrm{P \sigma}_{3} / \mathrm{mmc}$, of which the Al position is split (occupancy $1 / 2$ ) above and below the $\left(m_{z}\right)$ mirror plane (left). In $P 6_{3} m c$ Al1, Mg1, and Mg2 occupy three crystallographic (2b) sites (right). Atom types: $\mathrm{Mg}$ (red and brown), Al (grey with white front ellipsis), $\mathrm{Ca}$ (blue) and N (black). Unit cells are outlined with solid grey lines.

Table 2 Selected bond distances ( $(\AA)$ and bond angles $\left(^{\circ}\right)$ for $\mathrm{CaMg}_{2} \mathrm{AlN}_{3}$ calculated from the structure refinement in the space group $P 6_{3} / \mathrm{mmc}$

$\begin{array}{ll}\mathrm{Ca}-\mathrm{N} 1(6 \times) & 2.5767(4) \\ \mathrm{Mg}-\mathrm{N} 1(3 \times) & 2.0746(5) \\ \mathrm{Mg}-\mathrm{N} 2 & 2.0243(1) \\ \mathrm{Al}-\mathrm{N} 1 & 2.4208(1) \\ \mathrm{Al}-\mathrm{N} 3(3 \times) & 1.9851(6) \\ \mathrm{N} 1-\mathrm{Mg}-\mathrm{N} 2 & 108.447(5)\end{array}$

resulting in essentially tetrahedral coordination environments for all cations.

In order to validate the probability of one or the other space group by energy measures, the Madelung part of the lattice energy (MAPLE) was calculated for both structural models. ${ }^{24}$ Calculated MAPLE values for space group $\mathrm{PG}_{3} / \mathrm{mmc}$ and $P 6_{3} \mathrm{mc}$ are 25903 and $25926 \mathrm{~kJ} \mathrm{~mol}^{-1}$, respectively. Due to the similarity of both structural models, these values are quite close to each other and may indicate the possibility of a coexistence of both arrangements. Moreover, these MAPLE values represent the sum of the constituting binary nitrides with a deviation of less than $2 \%$.

The NMR analysis described in the following part of this article indicates that the correct space group is $\mathrm{PG}_{3} / \mathrm{mmc}$. Therefore, we focus our structural view on the assignment of the space group $P 6_{3} / m m c$ (no. 194) with lattice parameters $a=$ 3.4087(1) $\AA$ and $c=17.3760(5) \AA$ for two formula units $\mathrm{CaMg}_{2} \mathrm{AlN}_{3}$. The recorded diffraction pattern was fitted with two phases: $\mathrm{CaMg}_{2} \mathrm{AlN}_{3}$ and AlN as shown in Fig. 2. The rela-

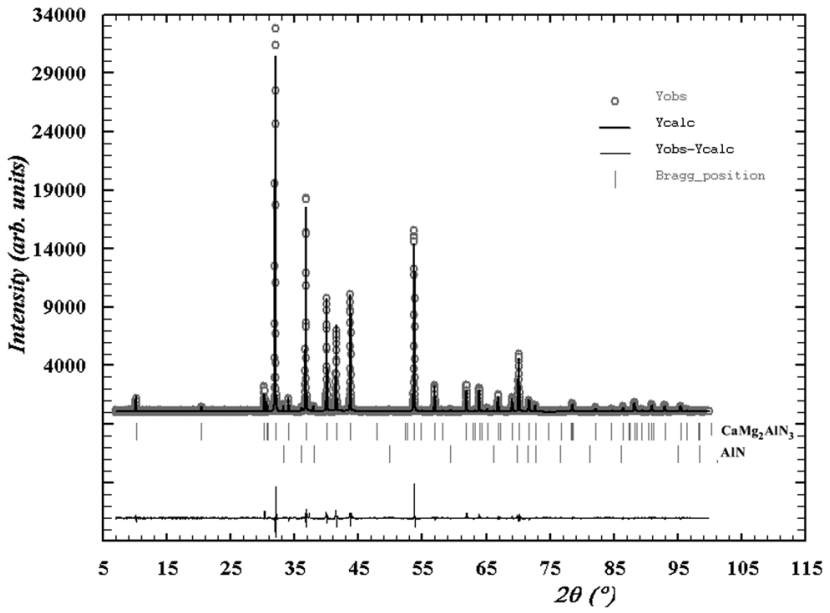

Fig. 2 Experimental XRD pattern and the corresponding reflexes for $\mathrm{CaMg}_{2} \mathrm{AlN}_{3}\left(P 6_{3} / \mathrm{mmc}\right)$ and AIN. Observed powder XRD pattern (grey circles), calculated pattern (black line), Bragg positions (grey ticks), and difference curve (black bottom line) after Rietveld refinement.

tive weight proportions of $\mathrm{CaMg}_{2} \mathrm{AlN}_{3}$ and AlN in the sample determined by Rietveld refinement were 97 and 3\%, respectively. The parameters of the refinement, obtained crystal data, and atomic coordinates are presented in Table 2. A pseudoVoigt profile function was used to fit the reflection peaks.

The crystal structure of $\mathrm{CaMg}_{2} \mathrm{AlN}_{3}$ is based on a hexagonal closest packing of nitride ions ( $\mathrm{N} 1$ and N2). One third of octahedral sites are occupied by $\mathrm{Ca}^{2+}$ and one half of tetrahedral sites are occupied by $\mathrm{Mg}^{2+}$ and $\mathrm{Al}^{3+}$ ions. The distributions of these cations result in a layered arrangement with two alternating layers, $[\mathrm{CaN}]^{+}$and $\left[\mathrm{Mg}_{2} \mathrm{AlN}_{2}\right]^{-}$, the first of which corresponds to the $\mathrm{NaCl}$ type, and the second corresponds to an $\mathrm{Al}_{4} \mathrm{C}_{3}$-type structure. These layers are stacked in an alternating fashion along the crystallographic $c$-axis direction. Projections of related $\mathrm{CaMg}_{2} \mathrm{AlN}_{3}, \mathrm{ScAl}_{3} \mathrm{C}_{3}, \mathrm{Al}_{4} \mathrm{C}_{3}$ and $\mathrm{Mg}_{3} \mathrm{BN}_{3}$ structures are shown in Fig. 3.

The bond lengths are summarized in Table 2. The distances between $\mathrm{Ca}^{2+}$ and $\mathrm{N} 1$ are in line with corresponding $\mathrm{Ca}-\mathrm{N}$ distances in $\mathrm{CaMg}_{2} \mathrm{~N}_{3}(2.596 \AA)$. ${ }^{11 a}$ The $\mathrm{Mg}-\mathrm{N}$ distances compare well with $\mathrm{Mg}-\mathrm{N}$ contacts in $\left[\mathrm{MgN}_{4}\right]$ tetrahedra of $\mathrm{Mg}_{3} \mathrm{~N}_{2}$ (2.085-2.179 $\AA)$, or $\mathrm{CaMg}_{2} \mathrm{~N}_{3}(2.128-2.296 \AA)$. Aluminum ions are known to have tetrahedral coordination environments with $\mathrm{N}^{3-}$ ions in nitrides. The Al-N2 distance for the trigonal environment of the $\left[\mathrm{AlN}_{4}\right]$ trigonal pyramid of $\mathrm{CaMg}_{2} \mathrm{AlN}_{3}$ is close to the Al-N distance in AlN (1.889-1.902 $\AA$ ) and in $\mathrm{Ca}_{3} \mathrm{Al}_{2} \mathrm{~N}_{4}(1.98 \AA)$. However, the Al-N1 distance with the pyramidal $\mathrm{N} 1$ is significantly longer. A mixed metal occupation is known for some nitride compounds, for example $\mathrm{Mg}_{3} \mathrm{GaN}_{3}$, with $\mathrm{Mg}^{2+}$ and $\mathrm{Ga}^{3+}$ ions occupying the same crystallographic site. ${ }^{9 a} \mathrm{~A}$ similar situation appears to exist in $\mathrm{CaMg}_{2} \mathrm{AlN}_{3}$, where partial occupation of the $\mathrm{Al}^{3+}$ site by $\mathrm{Mg}^{2+}$ ions (and vice versa) could result in an apparent lengthening of the Al-N1 contact.

\section{Second harmonic generation measurement}

A measurement of the second harmonic generation (SHG) effect was performed to get information about the presence or 


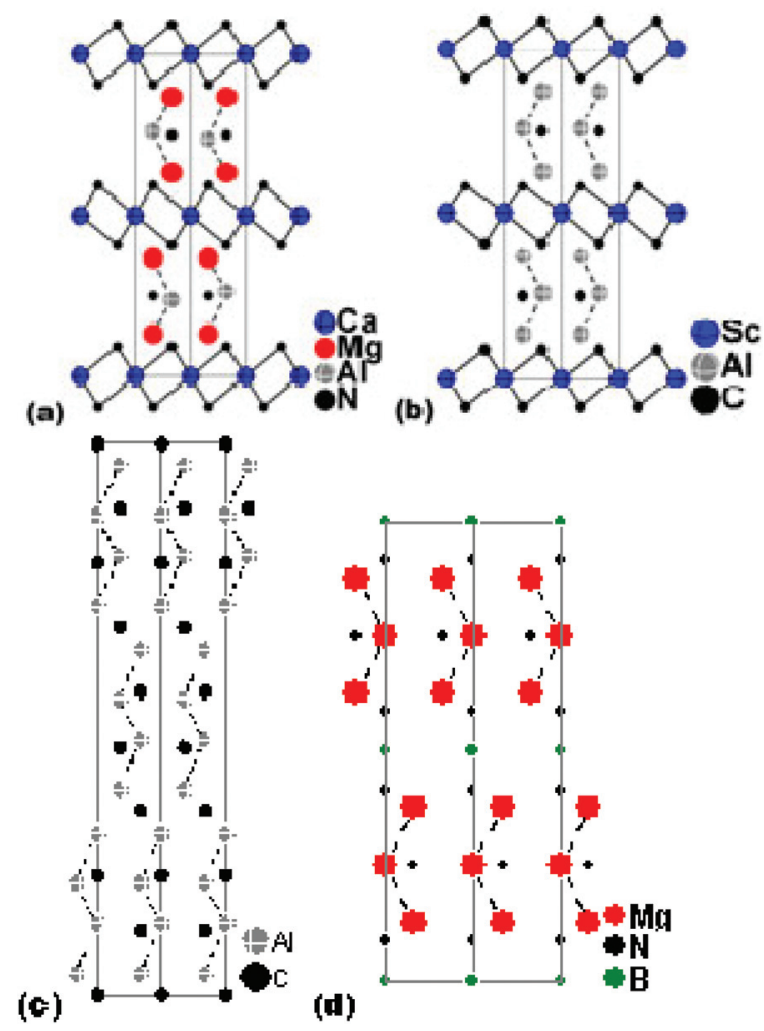

Fig. 3 Crystal structure of (a) $\mathrm{CaMg}_{2} \mathrm{AlN}_{3} P 6_{3} / m m c$, (b) $\mathrm{ScAl}_{3} \mathrm{C}_{3}$ $P 6_{3} m c^{24}$ (c) $\mathrm{Al}_{4} \mathrm{C}_{3} R \overline{3} m^{25}$ and (d) $\mathrm{Mg}_{3} \mathrm{BN}_{3} P 6_{3} / \mathrm{mmc}^{30}$ projected on the (110) plane. Atoms connected by solid lines represent $\mathrm{NaCl}$-type layers, atom connected by dashed lines can be related to $\mathrm{Al}_{4} \mathrm{C}_{3}$-type layers. Unit cells are outlined with solid grey lines.

absence of inversion symmetry in the structure. A SHG signal of the powder sample was not observed, in comparison to other noncentrosymmetric powders which clearly did show such an effect. This "observation" is consistent with the other evidence suggesting a centrosymmetric space group $\left(\mathrm{PG}_{3} / \mathrm{mmc}\right)$. However, it must be noted that only the opposite case, i.e., the appearance of a SHG signal (beyond surface SHG), can provide definitive proof of a noncentrosymmetric structure.

\section{${ }^{27} \mathrm{Al}$ and ${ }^{25} \mathrm{Mg}$ nuclear magnetic resonance}

In order to resolve the ambiguity between space groups, solidstate NMR and theoretical calculations were used to probe the coordination environments and measure the number of crystallographically inequivalent $\mathrm{Al}^{3+}$ and $\mathrm{Mg}^{2+}$ sites in $\mathrm{CaMg}_{2} \mathrm{AlN}_{3}$. Whereas these two elements have similar X-ray scattering cross-sections, their NMR spectroscopic responses are completely different and can be probed independently. ${ }^{27} \mathrm{Al} \mathrm{NMR}$ is well established and readily available on most solid-state NMR spectrometers, but ${ }^{25} \mathrm{Mg}$ NMR is less common and remains experimentally challenging even on state-of-theart ultrahigh-field NMR spectrometers. ${ }^{26}$ Besides its $10 \%$ natural abundance and quadrupolar nature, the low magnetogyric ratio of ${ }^{25} \mathrm{Mg}$ makes it inherently insensitive relative to many other typical NMR nuclei. To mitigate this limitation, all

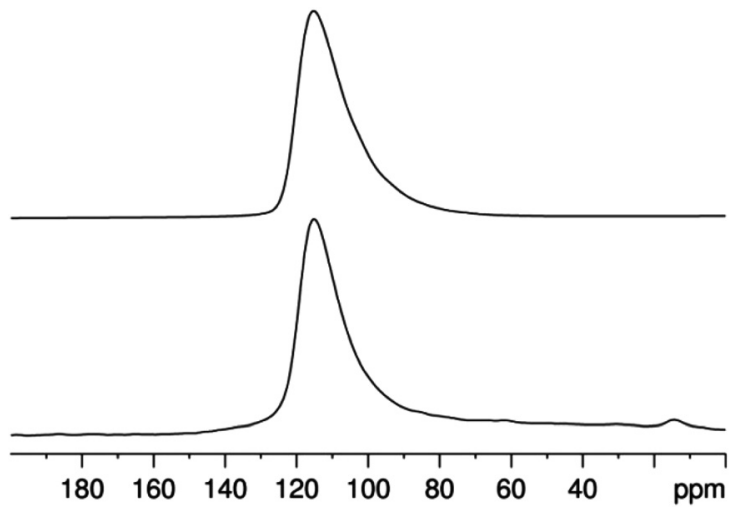

Fig. $4{ }^{27} \mathrm{Al}$ MAS NMR spectrum of $\mathrm{CaMg}_{2} \mathrm{AlN}_{3}$ acquired at $14.1 \mathrm{~T}$. The top trace is calculated using a Czjzek distribution with $\delta_{\text {iso }}=120 \pm$ $2 \mathrm{ppm}$ and $\mathrm{C}_{\mathrm{Q}}=5.6 \pm 0.2 \mathrm{MHz}$.

${ }^{25} \mathrm{Mg}$ NMR spectra were obtained using a $21.1 \mathrm{~T}$ magnet at the Canadian Ultrahigh-Field NMR Facility for Solids.

From an NMR perspective (i.e., short-range order), the structural differences between the proposed space groups are straightforward. $P 6_{3} / m m c$ (no. 194) is characterized by a single $\left[\mathrm{AlN}_{4}\right]$ site with highly distorted tetrahedral geometry and a single, slightly distorted $\left[\mathrm{MgN}_{4}\right]$ tetrahedron. $P 6_{3} m c$ (no. 186) possesses a single $\left[\mathrm{AlN}_{4}\right]$ site in a trigonal pyramidal environment and two distinct $\mathrm{Mg}$ sites, one in standard tetrahedral environment $(\mathrm{Mg} 2)$ and the other in trigonal pyramidal environment (Mg1). NMR is capable of quantifying the number of crystallographically inequivalent sites for each nucleus and measuring the quadrupole coupling constants $\left(C_{\mathrm{Q}}\right)$ at ${ }^{27} \mathrm{Al}$ and ${ }^{25} \mathrm{Mg}$ as a good indication of the degree of deviation from ideal tetrahedral symmetry. Pure cubic point symmetry produces a constant electric field at the cubic site, whereas geometric distortions generate progressively larger electric field gradients which couple with the nuclear electric quadrupole moment and thus produce the quadrupolar interaction. To assist in predicting the $C_{\mathrm{Q}} \mathrm{S}$ associated with a given geometric arrangement, theoretical calculations of the proposed structures were employed.

${ }^{27} \mathrm{Al}$ MAS NMR reveals a single peak with a chemical shift associated with the $\left[\mathrm{AlN}_{4}\right]$ environment (Fig. 4). ${ }^{27}$ The peak shape indicates the presence of structural disorder, appearing more like a typical glassy ${ }^{27} \mathrm{Al}$ NMR signal than a crystalline line shape. This spectrum was fit using a Czjzek model to account for the presence of local geometric distributions, ${ }^{15 b, 28}$ yielding an average quadrupole coupling constant in the range of 5.4 to $5.8 \mathrm{MHz}$. Long acquisitions times and a wide spectral window provided no evidence of a second aluminum site with a larger quadrupolar interaction.

Likewise, the ${ }^{25} \mathrm{Mg}$ MAS NMR spectrum consists of a single peak with a line shape indicative of disorder (Fig. 5). The chemical shift is consistent with a previous measurement of tetrahedral $\left[\mathrm{MgN}_{4}\right]$ in $\mathrm{Mg}_{3} \mathrm{~N}_{2}{ }^{29}$ and the line shape may be modelled as above using a single $\mathrm{Mg}$ site with $C_{\mathrm{Q}}=6.5 \pm$ $0.5 \mathrm{MHz}$. Considering the low intrinsic sensitivity of ${ }^{25} \mathrm{Mg}$ NMR and the possibility of broad signals exceeding the 


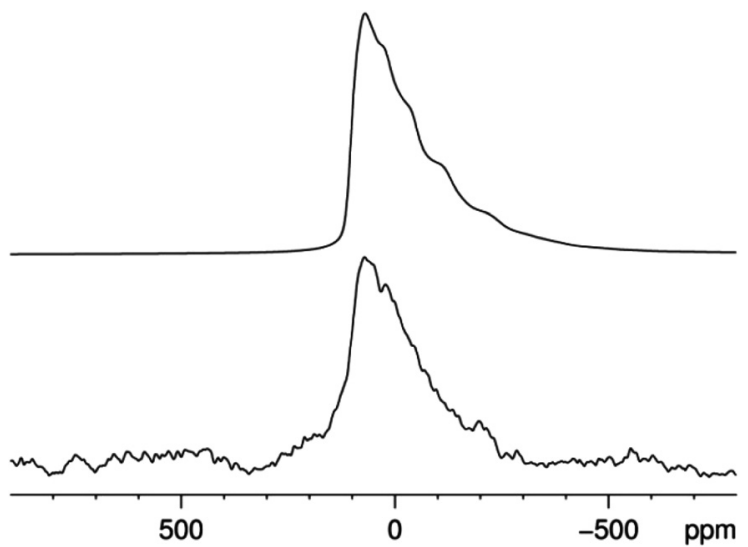

Fig. $5{ }^{25} \mathrm{Mg}$ MAS NMR spectrum of $\mathrm{CaMg}_{2} \mathrm{AlN}_{3}$ acquired at $21.1 \mathrm{~T}$. The top trace is calculated using a Czjzek distribution with $\delta_{\text {iso }}=100 \pm$ $5 \mathrm{ppm}$ and $\mathrm{C}_{\mathrm{Q}}=6.5 \pm 0.5 \mathrm{MHz}$.
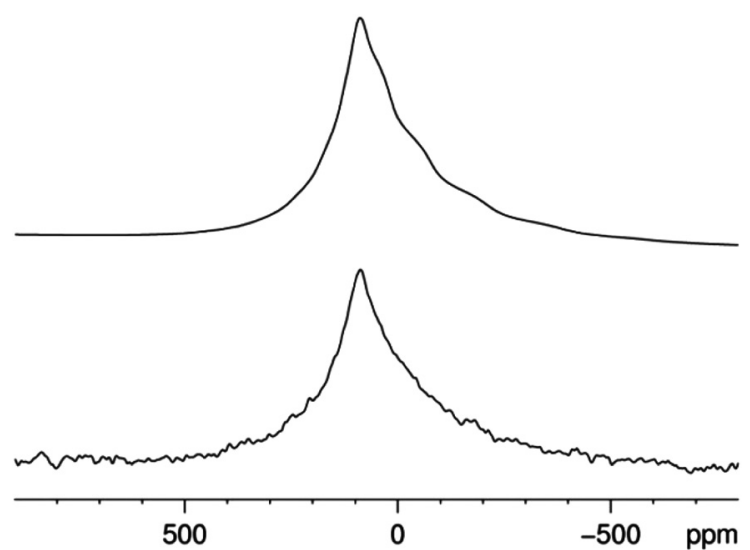

Fig. $6{ }^{25} \mathrm{Mg}$ quadrupole echo NMR spectrum of non-spinning $\mathrm{CaMg}_{2} \mathrm{AlN}_{3}$ acquired at $21.1 \mathrm{~T}$. The top trace is calculated using a Czjzek distribution of the central transition only with $\delta_{\text {iso }}=100 \pm 5 \mathrm{ppm}$ and $C_{Q}=6.5 \pm 0.5 \mathrm{MHz}$

spinning rate, a quadrupole-echo experiment on a non-spinning sample was acquired to seek additional intensity signifying a high- $C_{\mathrm{Q}}$ site (Fig. 6). The spectrum obtained can be successfully modelled using the same parameters as the ${ }^{25} \mathrm{Mg}$ MAS NMR spectrum and provides no evidence of additional sites. While the presence of structural disorder - and hence, a distribution of NMR parameters - implies that this fit may not be unique, it places an upper limit on the average value of $C_{\mathrm{Q}}$.

Even without calculations, these NMR results point toward $\mathrm{P6}_{3} / \mathrm{mmc}$ (194) as the correct space group, since there is no experimental evidence of the second $\mathrm{Mg}^{2+}$ site required by $\mathrm{P6}_{3} \mathrm{mc}$ (186). Gauge-including projector augmented wave (GIPAW) calculations ${ }^{17}$ provide a firmer basis for this conclusion by estimating the quadrupolar interactions expected for each of the putative space groups. GIPAW calculations of $\mathrm{P6}_{3} \mathrm{mc} \mathrm{CaMg}_{2} \mathrm{AlN}_{3}$ predicts a $C_{\mathrm{Q}}\left({ }^{27} \mathrm{Al}\right)$ of $6.4 \mathrm{MHz}$ and $C_{\mathrm{Q}}\left({ }^{25} \mathrm{Mg}\right)$ values of 2.9 and $17 \mathrm{MHz}$ for the four- and three-coordinate $\mathrm{Mg}$, respectively. Unusually large residual forces in the $c$-dimension resulting from direct usage of the X-ray coordinates suggested that geometry optimization may provide a more physically realistic structure. After energy minimization, the quadrupolar coupling constants changed to $C_{\mathrm{Q}}\left({ }^{27} \mathrm{Al}\right)=$ 9.2 $\mathrm{MHz}$ and $C_{\mathrm{Q}}\left({ }^{25} \mathrm{Mg}\right)=8$ and $19 \mathrm{MHz}$. While these values are substantially different than the unoptimized $C_{\mathrm{Q}} \mathrm{S}$, the main conclusion remains the same: two very different $\mathrm{Mg}$ sites are expected to be observed for this space group.

Due to the partial Al occupancy, GIPAW calculations of $\mathrm{P6}_{3} / \mathrm{mmc}$ (194) necessitated the use of a $2 \times 2 \times 1$ supercell. Various vacancy configurations gave a range of $C_{\mathrm{Q}}\left({ }^{25} \mathrm{Mg}\right)$ values between 1.3 and $6.2 \mathrm{MHz}$, while $C_{\mathrm{Q}}{ }^{27} \mathrm{Al}$ ) of the highly distorted $\left[\mathrm{AlN}_{4}\right]$ tetrahedron ranged from 9.5 to $10.3 \mathrm{MHz}$. While none of these calculations is expected to yield precise $C_{\mathrm{Q}}$ values - especially those for the disordered model - they serve as useful guidelines for the relative magnitudes associated with particular local geometries. As such, they provide a perspective on the experimental results, indicating that for this space group a single disordered $\mathrm{Mg}^{2+}$ and a single disordered $\mathrm{Al}^{3+}$ site is predicted, each with moderate quadrupolar coupling constants. The unusual geometry adopted by $\mathrm{Al}$ in the crystallographic refinement leads to calculated $C_{\mathrm{Q}}$ values which are likely overestimated since local distortions are expected to maximize tetrahedral regularity, consequently leading to reduced $C_{\mathrm{Q}} \mathrm{S}$. It is worth noting that the ${ }^{27} \mathrm{Al}$ chemical shift is in excellent agreement with that of pure wurtzite $\mathrm{AlN},{ }^{27}$ suggesting that the local Al symmetry is approaching tetrahedral. A full energy minimization of the supercell would be required to test this hypothesis, but is beyond our current computational capacity. The experimental data confirm that a single type of each cation is observed with moderate $C_{\mathrm{Q}}$ values, consistent with the $P 6_{3} / m m c$ space group. Perhaps most importantly, the spectral observation of a distribution of local $\mathrm{Mg}$ and $\mathrm{Al}$ geometric environments is compatible only with the space group implicating partial Al site occupancy, as subtle geometric distortions would undoubtedly accompany such vacancies and produce the observed line shapes. An alternate or additional explanation for this observation is that some degree of $\mathrm{Mg} / \mathrm{Al}$ antisite disorder is present in the structure, which is only expected in the $P 6_{3} / m m c$ space group.

\section{Luminescence spectroscopy}

The excitation, emission and reflection spectra measured at room temperature of $\mathrm{CaMg}_{2} \mathrm{AlN}_{3}$ are presented in Fig. 7 .

The reflection spectrum is composed of an absorption edge around $350 \mathrm{~nm}(3.54 \mathrm{eV})$, with an onset at $370 \mathrm{~nm}$. The main feature of the excitation spectrum is a broad band with a maximum at $330 \mathrm{~nm}$. Since excitation above $350 \mathrm{~nm}$ is not efficiently possible, the material is for the moment not of interest for solid state lighting, since (In,Ga)N chips emit between $370 \mathrm{~nm}$ and $500 \mathrm{~nm}$. The Gaussian-type emission band is likely caused by defects introduced by the flux during the solid state reaction. The possible origins of the luminescence are structural and point defects as well as impurities incorporated during the synthesis process which affect the electrical and optical properties of the nitride host. ${ }^{30}$ 


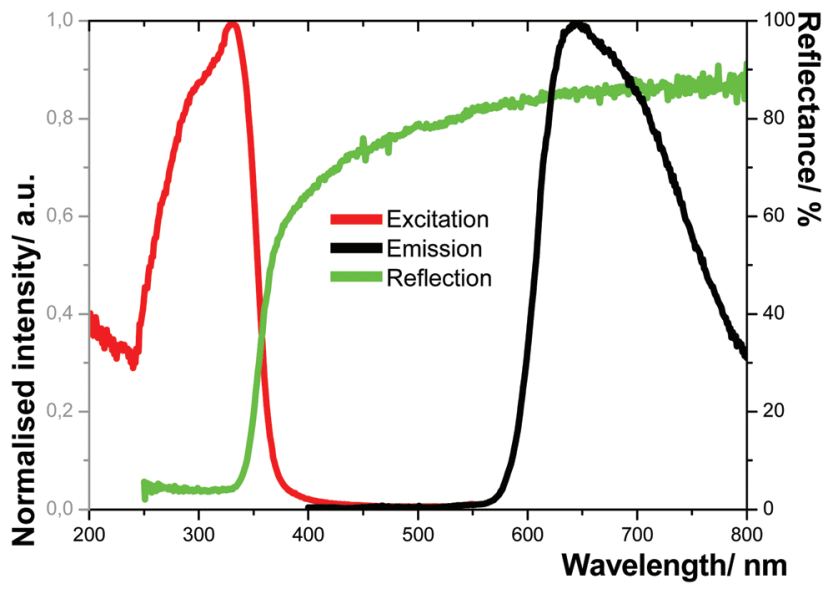

Fig. 7 Excitation, emission, and reflection spectra of $\mathrm{CaMg}_{2} \mathrm{AlN}_{3}$ synthesized with a flux, $\lambda_{\mathrm{Em}}=630 \mathrm{~nm}$ and $\lambda_{\mathrm{Ex}}=330 \mathrm{~nm}$.

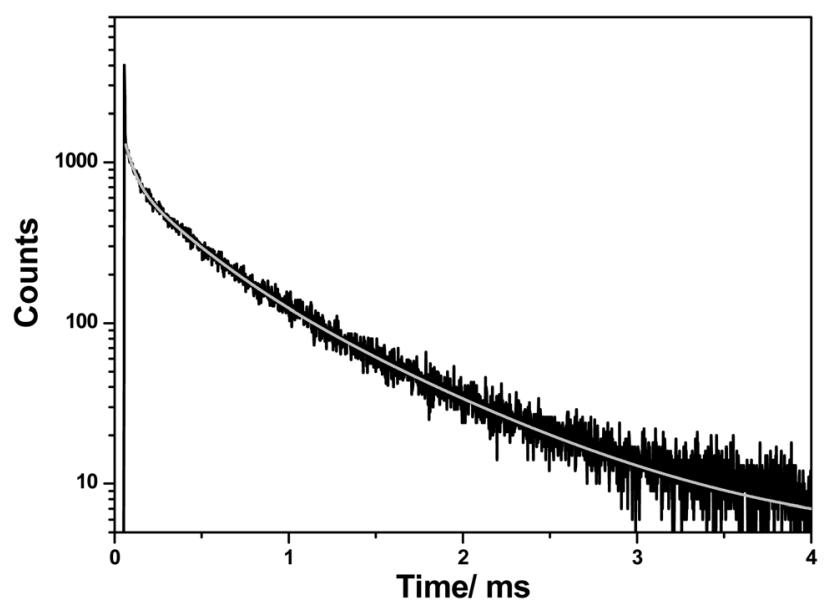

Fig. 8 Decay curve of $\mathrm{CaMg}_{2} \mathrm{AlN}_{3}$ monitored at $630 \mathrm{~nm}$ upon $330 \mathrm{~nm}$ excitation.

The full-width-half-maximum (FWHM) obtained for $\mathrm{CaMg}_{2} \mathrm{AlN}_{3}$ is about $152 \mathrm{~nm}$, much larger than for typical emission bands of $\mathrm{Eu}^{2+}$ ions in nitrides, for example 75 to $90 \mathrm{~nm}$ from $\mathrm{CaAlSiN}_{3}: \mathrm{Eu}^{2+}$ prepared by different methods. ${ }^{31}$ It is possible to draw a comparison between $\mathrm{CaMg}_{2} \mathrm{AlN}_{3}$ and the related compounds $\mathrm{MMg}_{2} \mathrm{Al}_{2} \mathrm{~N}_{4}: \mathrm{Eu}^{2+}(\mathrm{M}=\mathrm{Ca}, \mathrm{Sr}, \mathrm{Ba}) . \mathrm{BaMg}_{2} \mathrm{Al}_{2} \mathrm{~N}_{4}: \mathrm{Eu}^{2+}$ has similar luminescent properties even at room temperature with the large spectral width of emission (FWHM 115 nm) and large Stokes shift. ${ }^{18 c}$ These properties were ascribed to the emission from the trapped exciton states, for the calcium and strontium compound at higher temperatures a normal emission from $\mathrm{Eu}^{2+}$ ions was dominant.

Decay of the defect transition was investigated (Fig. 8), and the kinetics were determined by a multi-exponential decay curve fitted with three time constants $\tau_{1}=52 \pm 3(7 \%), \tau_{2}=$ $308 \pm 21(34 \%)$ and $\tau_{3}=817 \pm 35 \mu \mathrm{s}(59 \%)$. The values are significantly higher than for the $[\mathrm{Xe}] 4 \mathrm{f}^{6} 5 \mathrm{~d}^{1}-[\mathrm{Xe}] 4 \mathrm{f}^{7}$ transitions of $\mathrm{Eu}^{2+}$, usually about $1 \mu \mathrm{s} .{ }^{32}$ Defects in the crystal lattice lead usually to many pathways for the excitation energy and for this reason the luminescence lifetime of emission is long for such structure. A detailed explanation of the character of the luminescent centers with the measured lifetimes needs more study on structurally related and/or doped compounds.

\section{Conclusions}

$\mathrm{CaMg}_{2} \mathrm{AlN}_{3}$ was successfully synthesized in a closed system by solid state reaction, leading to a layered crystal structure. X-ray powder diffraction indicates two possible space groups: $P 6_{3} m c$ and $P 6_{3} / m m c$. The NMR results clearly indicate that the compound crystallizes in the space group $P 6_{3} / m m c$ (194) with a distorted tetrahedral environment around the aluminum atoms, including the possibility of a disordering of $\mathrm{Mg}^{2+}$ and $\mathrm{Al}^{3+}$ ions over opposite lattice sites in the structure. $\mathrm{CaMg}_{2} \mathrm{AlN}_{3}$ can undergo hydrolysis and oxidation, the same as most of the nitrides having low condensed network structures. The material prepared with a flux shows orange luminescence at room temperature. Its luminescence properties of this new material without a luminescent activator may open up a range of possible applications of undoped materials with advantages including broad, eye-friendly emission and cost efficiency. However, this requires a primary radiation source which emits below $350 \mathrm{~nm}$.

\section{Funding sources}

SK acknowledges the Natural Science and Engineering Research Council (NSERC) of Canada for operating support, and the Canada Foundation for Innovation (CFI) and the Manitoba Research Innovation Foundation (MRIF) for infrastructure funds. Access to the $900 \mathrm{MHz}$ NMR spectrometer was provided by the National Ultrahigh-Field NMR Facility for Solids (Ottawa, Canada), a Canadian research facility funded by CFI, the Ontario Innovation Trust, Recherche Québec, the National Research Council Canada, and BrukerBioSpin and managed by the University of Ottawa (http://www.nmr900.ca). NSERC is acknowledged for a Major Resources Support grant.

\section{Acknowledgements}

We like to express our gratitude to Dr Markus Ströbele and Dr Jochen Glaser for their help with the Rietveld refinement of the powder XRD data, and Dr Xiao Wang and Prof. Alfred Meixner from Eberhard-Karls-Universität Tübingen for SHG measurements. We are grateful to Drs Victor Terskikh and John Wren for technical assistance and helpful discussions.

\section{Notes and references}

1 D. G. Park, Y. Dong and F. J. DiSalvo, J. Solid State Chem., 2008, 10, 1846. 
2 M. Zeuner, S. Pagano and W. Schnick, Angew. Chem., Int. Ed., 2011, 50, 7754.

3 M. Kubus and H.-J. Meyer, Z. Anorg. Allg. Chem., 2013, 639, 669.

4 B. Lei, K. Machida, T. Horikawa and H. Hanzawa, Chem. Lett., 2010, 39, 104.

5 Z. A. Gal, P. M. Mallinson, H. J. Orchard and S. J. Clarke, Inorg. Chem., 2004, 43, 3998.

6 S. Pagano, S. Lupart, M. Zeuner and W. Schnick, Angew. Chem., Int. Ed., 2009, 121, 6453.

7 R. J. Bruls, H. T. Hintzen and R. Metselaar, J. Mater. Sci., 1999, 4, 4519.

8 S. T. Oyama, The Chemistry of Transition Metal Carbides and Nitrides, Blackie Academic \& Professiona, 1996.

9 (a) F. Hintze, N. W. Johnson, M. Seibald, D. Muir, A. Moewes and W. Schnick, Chem. Mater., 2013, 25, 4044; (b) W. Schnick and H. Huppertz, Chem. - Eur. J., 1997, 3, 679.

10 (a) M. Ludwig, R. Niewa and R. Kniep, Z. Naturforsch., B: Chem. Sci., 1999, 54, 461; (b) W. Blase, G. Cordier, M. Ludwig and R. Kniep, Z. Naturforsch., B: Chem. Sci., 1994, 49, 501.

11 (a) O. Reckeweg and F. J. Disalvo, Z. Anorg. Allg. Chem., 2001, 6, 371; (b) P. Pust, S. Pagano and W. Schnick, Eur. J. Inorg. Chem., 2013, 1157.

12 M. Ludwig, J. Jäger, R. Niewa and R. Kniep, Inorg. Chem., 2000, 39, 5909.

13 C. C. Lin and R. Liu, J. Phys. Chem. Lett., 2011, 2, 1268.

14 R. K. Harris, R. E. Wasylishen and M. J. Duer, NMR Crystallography, John Wiley and Sons, Chichester, UK, 2009.

15 (a) K. Eichele and R. E. Wasylishen, WSolids1 - Solid State NMR Simulations, Dalhousie University, Halifax, Canada, 2001; (b) D. Massiot, F. Fayon, M. Capron, I. King, S. Le Calve, B. Alonso, J. O. Durand, B. Bujoli, Z. H. Gan and G. Hoatson, Magn. Reson. Chem., 2002, 40, 70.

16 S. J. Clark, M. D. Segall, C. J. Pickard, P. J. Hasnip, M. J. Probert, K. Refson and M. C. Payne, Z. Kristallogr., 2005, 220, 567.

17 C. J. Pickard and F. Mauri, Phys. Rev. B: Condens. Matter, 2001, 63, 245101.

18 (a) O. Reckeweg, J. C. Molstad and F. J. DiSalvo, J. Alloys Compd., 2001, 315, 134; (b) A. N. Zhukov, K. P. Burdina and K. N. Semenenko, Russ. J. Gen. Chem., 1996, 66, 1046; (c) P. Pust, F. Hintze, C. Hecht, V. Weiler, A. Locher, D. Zitnanska, S. Harm, D. Wiechert, P. J. Schmidt and W. Schnick, Chem. Mater., 2014, 26, 6113; (d) T. Brokamp and H. Jacobs, J. Alloys Compd., 1992, 183, 325; (e) H. Yamane, T. H. Okabe, O. Ishiyama, Y. Waseda and M. Shimada, J. Alloys Compd., 2001, 319, 124.

19 T. M. Gesing and W. Jeitschko, J. Solid State Chem., 1998, 140, 396.

20 (a) A. O. Tsokol', O. I. Bodak, E. P. Marusin and M. G. Baivel'man, Sov. Phys. Crystallogr. (Engl. Transl.), 1986, 31, 467; (b) T.-M. Gesing, R. Pöttgen, W. Jeitschko and U. Wortmann, J. Alloys Compd., 1992, 186, 321.

21 (a) T. Roisnel and J. Rodriguez-Carvajal, WinPLOTR: A Windows Tool for Powder Diffraction Pattern Analysis, Paper presented at the Proceedings of the Seventh European Powder Diffraction Conference (EPDIC 7), 2000; (b) J. Rodriguez-Carvajal, Phys. B, 1993, 192, 55.

22 D. G. Park, Z. A. Gal and F. J. DiSalvo, Inorg. Chem., 2003, 42, 1779.

23 H. Hiraguchi, H. Hashizume, O. Fukunaga, A. Tekenaka and M. Sakato, J. Appl. Crystallogr., 1991, 24, 286.

24 R. Hübbenthal, MAPLE, Programm zur Berechnung des Madelunganteils der Gitterenergie, Version 4, Universität Gießen, Germany, 1993.

25 T. M. Gesing and W. Jeitschko, Z. Naturforsch., B: Chem. Sci., 1995, 50, 196.

26 I. L. Moudrakovski, Annu. Rep. NMR Spectrosc., 2013, 79, 129.

27 R. Dupree, M. H. Lewis and M. E. Smith, J. Appl. Crystallogr., 1988, 21, 109.

28 D. R. Neuville, L. Cormier and D. Massiot, Geochim. Cosmochim. Acta, 2004, 68, 5071.

29 P. J. Pallister, I. L. Moudrakovskii and J. A. Ripmeester, Phys. Chem. Chem. Phys., 2009, 11, 11487.

30 M. A. Reshchikov and H. Morkoc, J. Appl. Phys., 2005, 97, 061301.

31 (a) M. Mikami, H. Watanabe, K. Uheda, S. Shimooka, Y. Shimomura, T. Kurushima and N. Kijima, IOP Conf. Ser.: Mater. Sci. Eng., 2009, 1, 1-10; (b) X. Piao, K. Machida, T. Horikawa and H. Hanzawa, Chem. Mater., 2007, 19, 4592.

32 S. H. M. Poort, A. Meyerink and G. Blasse, J. Phys. Chem. Solids, 1997, 58, 1451. 